\title{
The childhood obesity epidemic: A mini review
}

Obesity is a medical condition resulting from the accumulation of excess fat in the human body to the extent that it might have great harm effects on the human health by increasing the diseases lowering the average life expectancy. A person who has a body mass index (BMI) of more than $30 \mathrm{~kg} / \mathrm{m}^{2}$ is classified as obese; this is how obesity can be defined for adult, which is different than that in children. To account for variability by sex and age, BMI in children must be compared with sexand age-specific reference values (Centers for Disease Control growth chart). The terminology that is used for high BMI-for-age in children in has been based on the recommendation of an expert committee convened by federal agencies. Parents can be a good example for their children by modeling healthful eating behaviors and being physically active. Parents can also be effective advocates by being involved in efforts in their schools, and community to expand the access and availability of opportunities for physical activity and healthful eating. In the case of being an obese child, that means suffering from many health problems and obesity-related diseases such as elevated blood pressure, high cholesterol, diabetes and heart diseases. Diabetes is considered as one of the obesity-related diseases; type 2 diabetes in children has linked with obesity; when the pancreas starts to produce the insulin hormone, excess body fat will not allow child's body to use the insulin as it should be which can lead to being a diabetic patient. Schools also play a vital role in teaching the students on how to eat properly and select the best meal with keeping their bodies flexible by doing physical activities. It is important in order to keep children away from being in disasters by having a lot of obesity-related diseases (e.g., heart attacks and diabetes), which can lead to premature death in obese children. Children must be healthy since those children growing up in today's world are tomorrow's future!

Key words: Childhood, diabetes, diet, heart disease, obesity

\section{INTRODUCTION}

\section{Lubna Mahmood}

Department of Health Sciences, Qatar University, Doha, Qatar

Address for the Correspondence:

Ms. Lubna Mahmood, Department of Health Sciences, Qatar University, Doha, Qatar, E-mail: Imahmood400@gmail.com

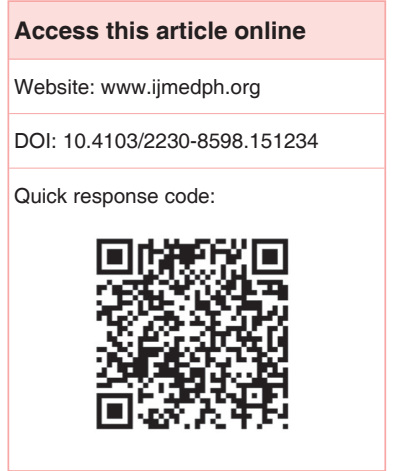

Obesity is a medical condition resulting from the accumulation of excess fat in the human body to the extent that it might have great harm effects on the human health by increasing the diseases lowering the average life expectancy. A person who has a body mass index (BMI) of more than $30 \mathrm{~kg} / \mathrm{m}^{2}$ is classified as obese; this is how obesity can be defined for adult, which is different than that in children. ${ }^{[1]}$ To account for variability by sex and age, BMI in children must be compared with sex- and age-specific reference values (Centers for Disease Control [CDC] growth chart). The terminology that is used for high BMI-for-age in children has been based on the recommendation of an expert committee convened by federal agencies.

The psychological effects of obesity and overweight should not be underestimated; a Canadian study showed that the overweight and obese children were more prone to low self-esteem than were healthyweight counterparts. This remained true 2 and 4 years from baseline. Children who participated in physical activity 5-7 times/week were less likely to have persistent low self-esteem than were those who rarely participated. ${ }^{[2]}$ Parents can be a good example for their children by modeling healthful eating behaviors and being physically active. Parents can also be effective advocates by being involved in efforts in their schools, and community to expand the access and availability of opportunities for physical activity and healthful eating. ${ }^{[3]}$ Few studies have examined the relationship between the activity levels of parents and their young children and found that the children of active mothers were twice as likely to be active as children of inactive mothers. ${ }^{[4]}$ There is a great relationship between the media and childhood obesity; television has been associated with childhood obesity since most of the children tend to spend most of their time watching TV and consuming large amounts of food full of sugar 
and fat, which lead to gain a lot of weight in a short period of time. Furthermore, the children's nature in imitating others can also play a great role with their weight; they love cartoons, pop stars, and some of the Hollywood actors, and they look at them as someone special and most of the time children make them as their role models. ${ }^{[5]}$

In the case of being an obese child, that means suffering from many health problems and obesity-related diseases such as elevated blood pressure, high cholesterol, diabetes and heart diseases. Diabetes is considered to be one of the obesity-related diseases; type 2 diabetes in children has linked with obesity; when the pancreas starts to produce the insulin hormone, excess body fat will not allow child's body to use the insulin as it should be which can lead to being a diabetic patient. ${ }^{[6]}$ Parents should also be aware of the social contexts in which foods are consumed, studies have demonstrated that children develop preferences for foods offered in positive contexts and conversely, are more likely to dislike foods offered in negative contexts. ${ }^{[7]}$ Parents should encourage healthful eating habits at home by making healthful foods available, increasing the number of family meals eaten together, and reducing the availability of sugarsweetened beverages and sodas. ${ }^{[6]}$ Now that many schools are making a commitment to soda-free cafeterias, parents can follow their lead and keep their homes free of sugar-sweetened beverages as well. ${ }^{[8]}$

\section{LITERATURE REVIEW}

\section{What qualifies as childhood obesity?}

Obesity is a medical condition resulting from the accumulation of excess fat in the human body to the extent that it might have great harm effects on the human health by increasing the diseases lowering the average life expectancy. A person who has a BMI of more than $30 \mathrm{~kg} / \mathrm{m}^{2}$ is classified as obese; this is how obesity can be defined for adult, which is different than that in children. ${ }^{[1]}$ To account for variability by sex and age, BMI in children must be compared with sex- and age-specific reference values (CDC growth chart). The terminology that is used for high BMI-for-age in children, has been based on the recommendation of an expert committee convened by federal agencies. This committee has recommended the use of BMI and defined overweight as a BMI-for-age at or above the $95^{\text {th }}$ percentile of a specified reference population, while those "at risk for overweight" are having BMI values between the $85^{\text {th }}$ and the $95^{\text {th }}$ percentiles of BMI for age. ${ }^{[9]}$ Childhood obesity is a major public health crisis nationally and internationally; the prevalence of childhood obesity has increased over few years. Childhood obesity is on the rise; it has become a serious public health concern in all over the world. ${ }^{[10]}$

\section{Causes and risk factors of childhood obesity}

One study showed that the risk of becoming overweight was decreased by $4 \%$ for each month of breastfeeding in the. One study showed that the risk of becoming overweight was decreased by $4 \%$ for each month of breastfeeding in the first 9 months of life; this benefit plateaued after 9 months of breastfeeding first 9 months of life; this benefit plateaued after 9 months of breastfeeding Obese children are more likely to be obese in adulthood than healthy-weight children; also they are at higher risk of certain conditions in adulthood, including components of the metabolic syndrome, cardiovascular disease, and several types of cancer. It is becoming increasingly apparent, however, that obese children are at high immediate risk of conditions previously not even seen in children. ${ }^{[1]}$ The psychological effects of obesity and overweight should not be underestimated; a Canadian study showed that the overweight and obese children were more prone to low selfesteem than were healthy-weight counterparts. This remained true 2 and 4 years from baseline. Children who participated in physical activity 5-7 times/week were less likely to have persistent low selfesteem than were those who rarely participated. ${ }^{[2]}$ Environmental, socioeconomic, and lifestyle risk factors often overlap, in that environmental factor can result in unhealthy diets and insufficient physical activity. Family physicians should consider genetic and medical risk factors for overweight and obesity. In addition to isolated gene effects, certain rare genetic disorders, such as PraderWilli, Bardet-Biedl, and Alström syndromes, can lead to obesity in children. ${ }^{[12]}$ Excess gestational weight gain has been associated with early childhood obesity, and obesity in childhood is likely to persist into adulthood. In addition, infants born to obese mothers are more likely to be obese in later years. One study showed that the risk of becoming overweight was decreased by $4 \%$ for each month of breastfeeding in the first 9 months of life; this benefit plateaued after 9 months of breastfeeding. ${ }^{[13]}$

\section{The effect of parents on children obesity}

Parents can be a good example for their children by modeling healthful eating behaviors and being physically active. Parents can also be effective advocates by being involved in efforts in their schools, and community to expand the access and availability of opportunities for physical activity and healthful eating. ${ }^{[3]}$ Parenting influences the development of overweight and obesity in various ways at different stages of a child's development; the children of mothers who suffer from diabetes mellitus, gestational diabetes, and under-nutrition and over-nutrition during pregnancy are at particular risk for obesity, with the greatest risk factor being gestational diabetes. Several studies, for example, have documented lower rates of overweight among children who were breast-fed for longer durations. ${ }^{[14]}$ Few studies have examined the relationship between the activity levels of parents and their young children and found that the children of active mothers were twice as likely to be active as children of inactive mothers. ${ }^{[4]}$

\section{The media, food advertisements and environmental factors}

There is a great relationship between the media and childhood obesity; television has been associated with childhood obesity since most of the children tend to spend most of their time watching TV and consuming large amounts of food full of sugar and fat which lead to gain a lot of weight in a short period of time. Furthermore, 
the children's nature in imitating others can also play a great role with their weight; they love cartoons, pop stars, and some of the Hollywood actors, and they look at them as someone special and most of the time children make them as their role models. ${ }^{\left[{ }^{[3]}\right.}$ When a cartoon character represents some food advertisements (e.g., fast food and candies), which is not suitable for children's health, Based on a scientific study has studies the relationship between watching TV and increasing the BMI of children has found that the group of young children were unable to distinguish between the television advertising and the program that was surrounded it, while the group of younger than 7-year-old children were unable to understand the intent of the advertising which was to sell them food that might affect their health negatively and hence they conclude that the relationship watching Television and getting obesity among children was due to the commercial television viewing and the effects of advertising obesogenic foods on television. ${ }^{[15]}$

The same thing for the schools' meals; since children spent most of their time in school, so logically they will need to have more than one meal. The new school meal standards are being phased in by the government in order to make sure that children can meet their nutrients needs. A research study "Food and nutrient of primary school children: A comparison of school with a sample of 120 children, their age were vary from 6 to 11 years old has demonstrated the effect of schools meals on children's body weight; items consumed were recorded at a lunch time and the nutritional analysis was performed. Later, they determined that the amount of energy provided from those different meals was the same, but the packed meal was different from the school meals in providing the needed amount from energy as well as other nutrients included calcium and iron, but more saturated fat, which can lead to gain weight, while the school meals provide more energy from fat with less amount of minerals, but these meals are lower in saturated fat. The study concluded that children who are taking packed lunch meal with them to their school are consuming the double amount of sugar and saturated fat compared with those having school meals. Although packed lunches have more mineral but still less healthy than the school meals because of the large amount of saturated fat. ${ }^{[16]}$ Children can get obesity due to special meals that they consume such the packed lunches, and fast food restaurant; fast foods can contribute a lot to childhood obesity since fast food is served in a large amount and big size, moreover, those restaurants are responsible for at least half of the childhood obesity in the societies. Children tend to eat a lot of burgers, pizza, fries, and coke products which have no nutrient that their body need, but instead of that, these types of food provide the children a lot fatty food with no nutritional value, and that why most of obese children suffer from heart diseases and diabetes. ${ }^{[17]}$ A scientific research has determined the effect of fast foods on childhood food products by developing samples from two different sources of primary children schools, one from 10 private primary school in Jakarta and the other is from 10 state primary school in Semarang. The data have been collected by using a special questionnaire which based on exploratory research; it has been found that the products attributes trend, characteristics, products feeling, the taste of the products, whereas the price doesn't stimulate the development of children consumption since most of children don't pay attention to the characteristics of food products. Also, it has been demonstrated that the fast food restaurants had a great impact on children consumption that's why children have a positive attitude toward the products even when they were at the age of 3 -year-old. ${ }^{[18]}$

Children's weight might be influenced by lots of environmental factors such as social factors and physical activity; healthy lifestyle habits can lower the risk of getting obesity and preventing some related diseases. Excess body weight can be gained because of an energy imbalance, which is provided from the extra consumed foods and no physical activities. ${ }^{[7]}$ as "Obesogenic" is known as that environment with large impacts on a children by letting them have the ability to gain weight, these environment include consuming large portions and sizes of food, high fat diet, high sugar intake, spending most of the time in watching TV without doing any others activity such as sports. Physical activity level influences the risk of obesity by their effects on the energy expenditure; children are susceptible to obesity and preschool children are believed not to be obese as they are highly physically-active. As the world developed, childhood obesity is being increased (e.g., in recent treatment trial, children with the age of 8-year-old have a body weight of $52 \mathrm{~kg}$, which is approximately from 15 to $20 \mathrm{~kg}$ above the normal weight of children with this age, and that is because the obesogenic behaviors during the preschool period supposed to be very common in the developed world. That's why the public health start to put their great efforts in the preschool period to prevent the obesity and to limit the rate of getting obesity after this period. ${ }^{[19]}$

\section{Childhood obesity and health issues}

In the case of being an obese child, that means suffering from many health problems and obesity-related diseases such as elevated blood pressure, high cholesterol, diabetes, and heart diseases. Diabetes is considered as one of the obesity-related diseases; type 2 diabetes in children has linked with obesity; when the pancreas starts to produce the insulin hormone, excess body fat will not allow child's body to use the insulin as it should be which can lead to being a diabetic patient. ${ }^{[6]}$ Weight gain has a negative impact on glycaemia; also, it can lead to harm the pancreas, insulin secretion process, and other glands. Researchers have found that patients on sulfonylureas or insulin increased their body weight by $4.0 \mathrm{~kg}$ and from 1.7 to $2.6 \mathrm{~kg}$; gaining more weight than normal is considered as catastrophic and a disaster for diabetic patients who have struggled for many years trying to lose the excess weight or at least maintain their weight on the normal ranges, because there is protein, which released from fat cells into blood stream and it can cause the children body to become desensitized to insulin, which means that the pancreas will start to produce more insulin in order to counteract the negative effects, and then because of large amount insulin secretion, the pancreas will become overworked and slow down or even stop the releasing of insulin, which could lead to diabetes. ${ }^{[20]}$ 
Suffering from heart diseases is a common negative effect of being obese children, because of the overworking load on the heart. Obesity is mostly associated with heart failure, heart disease and heart attack are the most causes of premature death in obese children, and heart disease is caused due to heart muscles death and losing the ability of supplying the enough amount of oxygen, since the blood can be blocked flow by fat accumulations. In this case the heart will suffer from a great load in order to do its overwork without oxygen supplies, and then the heart may suddenly stop beating and lead to child death. ${ }^{[8]}$ Based on a scientific research studies the effect of obesity on heart diseases has found that there was a positive relationship between childhood obesity and heart diseases, this study concluded that the relationship are dependent on the BMI of children, evidence suggested that the risk of raised blood pressure is highest in those with a lower end of the BMI scale, while the interventions during childhood is important in the prevention of adult obesity, however it is important to avoid the negative consequences when the timing starts to coincide with critical stages of behavioral, neurological, and physical development. ${ }^{[1]}$

\section{Suggested solutions}

Parents should also be aware of the social contexts in which foods are consumed; studies have demonstrated that children develop preferences for foods offered in positive contexts and conversely, are more likely to dislike foods offered in negative contexts. ${ }^{[7]}$ During preschool age, children particularly start to dislike new foods, hence it becomes important for parents to model healthful eating habits and to offer a variety of healthful foods to their children. Studies' findings suggested that parents should encourage outdoor play since children of active mothers were twice as likely to be active as children of inactive mothers. Parents should encourage healthful eating habits at home by making healthful foods available, increasing the number of family meals eaten together, and reducing the availability of sugarsweetened beverages and sodas. ${ }^{[6]}$ Now that many schools are making a commitment to soda-free cafeterias, parents can follow their lead and keep their homes free of sugar-sweetened beverages as well. ${ }^{\left[{ }^{[}\right]}$

\section{CONCLUSION}

Media attraction, fatty meals, and environment factors all can play a great role in increasing the children susceptibility to gain more weight and being obese. Parental control is very important by determine, which food advertisement the children should see, and also in selecting the best meals for them which should be better than fast food and meet their body needs as children. Schools also play a vital role in teaching the students on how to eat properly and choose the best meal with keeping their bodies flexible by doing physical activities. All the above is important in order to keep children away from being in disasters by having a lot of obesity-related diseases (e.g., heart attacks and diabetes), which can lead to pre-mature death in obese children. Children must be healthy since those children growing up in today's world are tomorrow's future!

\section{REFERENCES}

1. Solveig A, Micheal R, Venket K. Incidence of childhood obesity in the united states. The N Engl J Med 2014;370:403-11.

2. Lo JC, Chandra M, Sinaiko A, Daniels SR, Prineas RJ, Maring B, et al. Severe obesity in children: Prevalence, persistence and relation to hypertension. Int J Pediatr Endocrinol 2014;2014:3.

3. Mahshid D, Noori A, Anwer T. Childhood obesity: Prevelance, and prevention. Nutr J 2005;24:1-8.

4. Rao G. Childhood obesity: Highlights of AMA Expert Committee recommendations. Am Fam Physician 2008;78:56-63.

5. Wang F, Wild TC, Kipp W, Kuhle S, Veugelers PJ. The influence of childhood obesity on the development of self-esteem. Health Rep 2009;20:21-7.

6. Harrington JW, Nguyen VQ, Paulson JF, Garland R, Pasquinelli L, Lewis D. Identifying the "tipping point" age for overweight pediatric patients. Clin Pediatr (Phila) 2010;49:638-43.

7. Harder T, Bergmann R, Kallischnigg G, Plagemann A. Duration of breastfeeding and risk of overweight: A meta-analysis. Am J Epidemiol 2005;162:397-403.

8. Whitaker RC, Dietz WH. Role of the prenatal environment in the development of obesity. J Pediatr 1998;132:768-76.

9. Westenhoefer J. Establishing dietary habits during childhood for longterm weight control. Ann Nutr Metab 2002;46 Suppl 1:18-23.

10. Trost SG, Sallis JF, Pate RR, Freedson PS, Taylor WC, Dowda M. Evaluating a model of parental influence on youth physical activity. Am $J$ Prev Med 2003;25:277-82.

11. Dubois L, Farmer A, Girard M, Peterson K. Social factors and television use during meals and snacks is associated with higher BMI among pre-school children. Public Health Nutr 2008;11:1267-79.

12. Bell J, Zimmerman F. Association of television content type and obesity in children. J Am Public Health 2010;100:334-40.

13. Rees GA, Richards CJ, Gregory J. Food and nutrient intakes of primary school children: A comparison of school meals and packed lunches. J Hum Nutr Diet 2008;21:420-7.

14. Haryanto J, Wiharto B. Determinant of the children intention to consume fast food products. J Makara Sosial Humaniora 2009;13:29-36.

15. Sameera K, Amar K. Childhood obesity: A global public health crisis. Int J Prev Med 2012;3:1-7.

16. Oliveria SA, Ellison RC, Moore LL, Gillman MW, Garrahie EJ, Singer MR. Parent-child relationships in nutrient intake: The Framingham Children's Study. Am J Clin Nutr 1992;56:593-8.

17. Brug J, Kremers SP, Lenthe Fv, Ball K, Crawford D. Environmental determinants of healthy eating: In need of theory and evidence. Proc Nutr Soc 2008;67:307-16.

18. Powell KE, Martin LM, Chowdhury PP. Places to walk: Convenience and regular physical activity. Am J Public Health 2003;93:1519-21.

19. Haslam D. Obesity and diabetes: The link and common approaches. J Prim Care Diabetes 2010;4:105-12.

20. James J, Thomas P, Cavan D, Kerr D. Preventing childhood obesity by reducing consumption of carbonated drinks: Cluster randomised controlled trial. BMJ 2004;328:1237.

21. Evans S, Lloyd L, McMullen S. Childhood obesity and adult cardiovascular disease risk: A systematic review. J Obes 2010;34:18-28.

How to cite this article: Mahmood L. The childhood obesity epidemic: A mini review. Int J Med Public Health 2015;5:6-9.

Source of Support: Nil, Conflict of Interest: None declared. 